\title{
ÁCIDOS SIÁLICOS - DA COMPREENSÃO DO SEU ENVOLVIMENTO EM PROCESSOS BIOLÓGICOS AO DESENVOLVIMENTO DE FÁRMACOS CONTRA O AGENTE ETIOLÓGICO DA GRIPE
}

\author{
Ângelo de Fátima*, Lúcia Helena Brito Baptistella e Ronaldo Aloise Pilli \\ Departamento de Química Orgânica, Instituto de Química, Universidade Estadual de Campinas, CP 6154, 13084-971 Campinas - SP \\ Luzia Valentina Modolo \\ Departamento de Bioquímica, Instituto de Biologia, Universidade Estadual de Campinas, CP 6109, 13083-970 Campinas - SP
}

Recebido em 4/2/04; aceito em 13/7/04; publicado na web em 23/11/04

\begin{abstract}
SIALIC ACIDS - FROM THE COMPREHENSION OF THEIR INVOLVEMENT IN BIOLOGICAL PROCESSES TO ANTIINFLUENZA DRUG DESIGN. Sialic acids are nine-carbon carbohydrates that occur widely in nature and occupy the terminal portions of some glycoproteins and glycolipids of cell membranes. These carbohydrates are closely involved in cell-cell interactions and in processes such as microbial infection, inflammation, etc. Studies on the participation of sialic acids in biological processes have provided comprehension about their role in the infection by the influenza virus, the causal agent of flu. In this article, we present an overview of the importance of sialic acids in the influenza virus infection and how the knowledge of their involvement in this process has allowed the development of selective and efficient drugs against the virus.
\end{abstract}

Keywords: sialic acid; flu and antiinfluenza drugs.

\section{INTRODUÇÃO}

Não há vida sem célula. E a exemplo da própria vida, que tanta diversidade apresenta, variam as formas e funções das células. As células são as unidades estruturais e funcionais de todos os organismos e é possível reconhecer, em sua hierarquia estrutural, alguns níveis de complexidade, como aqueles presentes, por exemplo, em uma célula vegetal: $\boldsymbol{o}$ nível 3 onde se incluem complexos supramoleculares (cromossomo, membrana plasmática, parede celular, etc); o nível 2 representado por macromoléculas (DNA, proteínas, celulose, etc) e o nível 1 compreendendo as unidades monoméricas, como nucleotídeos, aminoácidos, carboidratos, $\operatorname{etc}^{1-3}$ (Figura 1).
A membrana plasmática, presente em células de todas as espécies, define a periferia da célula, separando o seu conteúdo da circunvizinhança. Ela serve como uma barreira de permeabilidade, que permite à célula manter uma composição citoplasmática e é composta de grande número de moléculas de lipídios e proteínas que se mantêm juntas principalmente por interações hidrofóbicas, formando uma bicamada lipídica fina, resistente e flexível, em volta da célula ${ }^{1-3}$. Algumas proteínas presentes na membrana celular permitem a passagem de certos íons e moléculas (proteínas transportadoras). Outras proteínas exercem o papel de receptores, transmitindo o sinal do exterior para o interior da célula. Há ainda proteínas que funcionam como enzimas, participando de reações que ocorrem em membranas. Mui-

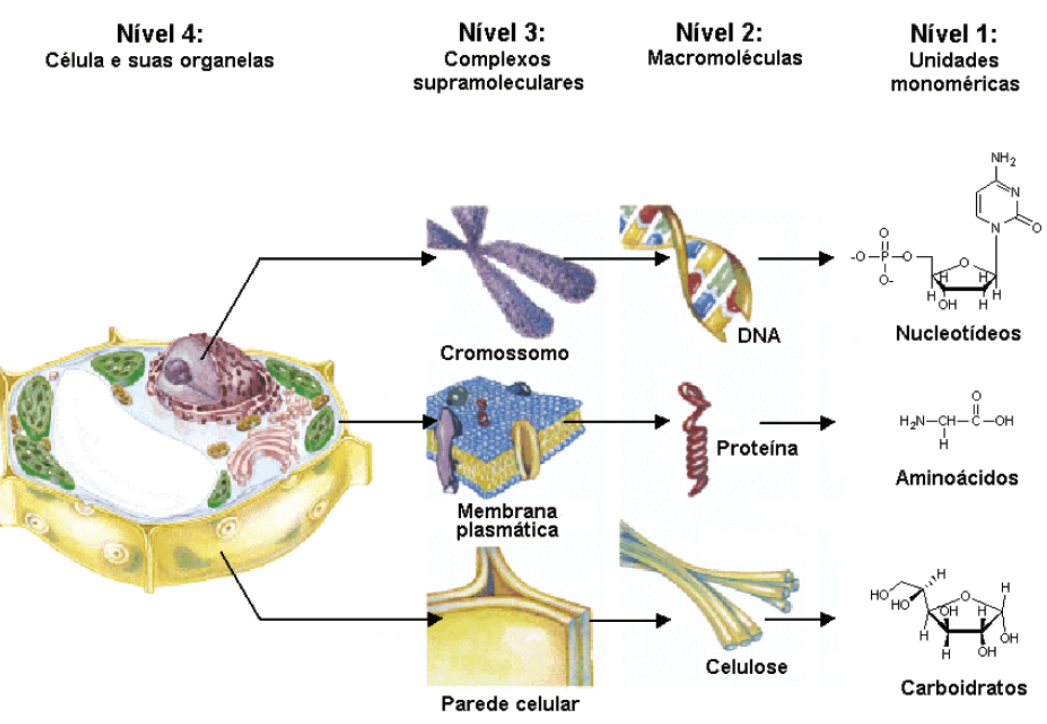

Figura 1. Hierarquia estrutural na organização molecular de uma célula vegetal. Reproduzido da ref. 1, com permissão de W. H. Freeman and Company/ Worth Publishers 
tas das proteínas e dos lipídeos presentes na membrana celular apresentam-se como conjugados de carboidratos, denominando-se glicoproteínas e glicolipídeos, respectivamente ${ }^{1-4}$ (Figura 2). As glicoproteínas, em especial, são fundamentais em muitos processos biológicos incluindo fertilização, ativação do sistema imune, replicação viral, crescimento e renovação celular e inflamação, entre outros ${ }^{5}$.

Dentre os carboidratos presentes nos glicoconjugados de membrana destacam-se os ácidos siálicos, uma família de carboidratos complexos de nove carbonos, normalmente ligados a outros carboidratos por meio de ligações $\alpha$-cetosídicas, que ocorrem na natureza em cerca de 50 tipos. Estes tipos diferem entre si por variações do grau de substituição e oxidação no esqueleto carbônico e têm como molécula precursora a $N$-acetil-D-manosamina (ManNAc) ${ }^{6}$ (Figura 3). Este precursor é biossintetizado a partir de UDP- $N$-acetilD-glicosamina, uma molécula obtida em meio intracelular ${ }^{7}$ ou a partir da $N$-acetil-D-glicosamina (GlcNAc), com participação da enzima $\mathrm{N}$-acetil-D-glicosamina-2-epimerase ${ }^{8}$ (Figura 3). A $\mathrm{N}$-acetil-D- manosamina produzida é fosforilada em C6 pela enzima $N$-acetil-Dmanosamina-6-quinase. A ação da enzima Neu5Ac aldolase (também conhecida como ácido siálico 9-P sintase) sobre a $N$-acetil-Dmanosamina 6-fosfato, na presença de fosfoenolpiruvato (FEP), gera uma base de Schiff e, subseqüentemente, o ácido siálico-9-P (ácido $\mathrm{N}$-acetilneuramínico 9-fosfato) (Figura 3). A perda do grupamento fosfato, mediada pela enzima ácido siálico 9-fosfato fosfatase fornece o ácido siálico (ácido $N$-acetilneuramínico - Neu5Ac) livre que é direcionado ao núcleo da célula. Neste compartimento, o ácido $N$ acetilneuramínico (Neu5Ac) é ativado à custa de hidrólise de citidina trifosfato (CTP), sendo formado CMP-ácido siálico que é transportado para o complexo de Golgi. Nesta organela, CMP-ácido siálico atuará como doador de glicosídeo no processo de alongamento de cadeias dos oligossacarídeos de glicoproteínas e glicolipídeos, por ação de enzimas denominadas sialiltransferases ${ }^{9,10}$ (Figura 3). Assim, glicoproteínas ou glicolipídeos sialilados são secretados ou entregues à membrana plasmática da célula.

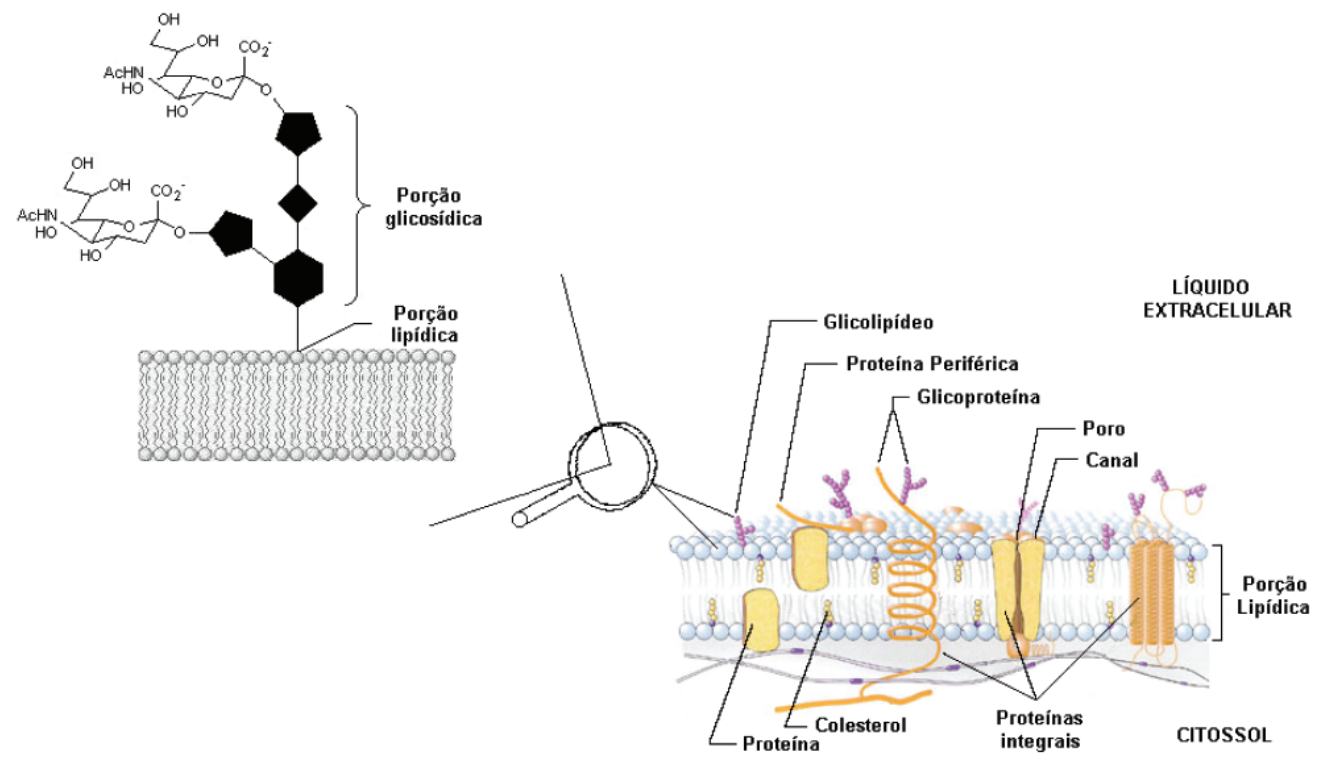

Figura 2. Estrutura da membrana celular, com ampliação para um glicolipídeo de membrana. Adaptado da ref. 4

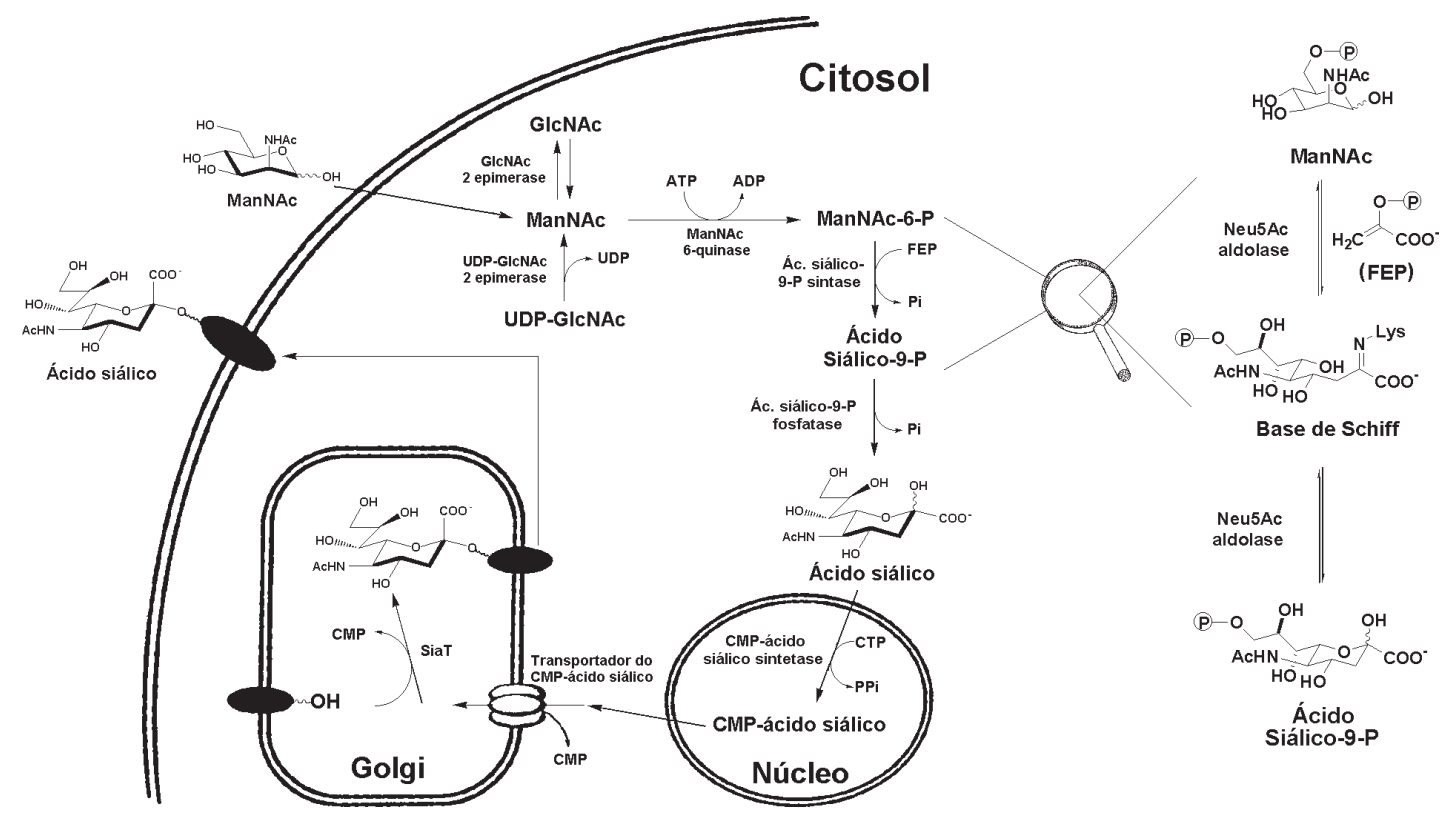

Figura 3. Rota simplificada da biossíntese do Neu5Ac 
O ácido siálico mais abundante existente em eucariotos é o ácido $\mathrm{N}$-acetilneuramínico (ácido 5-acetamido-3,5-didesoxi-D-glicero- $\alpha$ D-galacto-non-2-ulopiranosônico - Neu5Ac, 1), que foi isolado pela primeira vez por Gottschalk e colaboradores ${ }^{11,12}$. Outros derivados comuns, porém encontrados em menor quantidade, são ácido $N$ glicosilneuramínico $(\mathrm{Neu} 5 \mathrm{Gl}, 2)$ e 5-hidroxineuramínico (ácido 3desoxi-D-glicero- $\alpha$-D-galacto-non-2-ulopiranosônico - KDN, 3) (Figura 4$)^{11}$. Foi relatada a ocorrência de derivados dos ácidos siálicos $\mathbf{1}, \mathbf{2}$ e $\mathbf{3}$ que incorporam em suas estruturas um ou mais grupos acetilas, ou envolvem a lactonização ou fosforilação da hidroxila em C9 ou a metilação ou sulfatação da hidroxila em C8. Como componentes de glicoconjugados, os ácidos siálicos são encontrados ligados a hexoses, como $\alpha(2,3)$ - ou $\alpha(2,6)-\beta$-Gal ou $\beta$-GalNHR e ligados a outros ácidos siálicos como $\alpha(2,8)^{11,13}$.

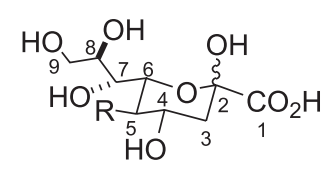

$$
\begin{aligned}
& R=\text { NHAc (Neu5Ac, 1) } \\
& R=\text { NHGlicosil (Neu5GI, 2) } \\
& R=O H(K D N, 3)
\end{aligned}
$$

Figura 4. Estruturas dos ácidos siálicos mais comuns

Localizados nas posições terminais de glicoconjugados da superfície celular (Figura 2), os ácidos siálicos estão intimamente envolvidos em processos biológicos fundamentais à manutenção da vida, mas em funções diferentes daquelas normalmente atribuídas a carboidratos como armazenadores de energia (glicogênio e amido, por exemplo) ou como componentes de blocos estruturais (quitina e celulose $)^{1-3}$. Exemplos do envolvimento dos ácidos siálicos em processos biológicos incluem as funções de mediadores na adesão célula-célula, mediadores na comunicação intercelular, renovadores celulares, receptores para bactérias e vírus, entre outras ${ }^{14-17}$.

Como mediadores na renovação celular, pode-se citar o papel dos ácidos siálicos em eritrócitos. Os eritrócitos são células que se formam na medula óssea e que, ao atingirem a maturação, passam ao sangue e têm como principal função o transporte de oxigênio a todos os tecidos do corpo. Um dos eventos biológicos que determinam a "idade" do eritrócito, cuja vida média é de aproximadamente 120 dias, é a perda dos resíduos de ácidos siálicos presentes em seus glicoconjugados de membrana. As unidades de ácidos siálicos encontradas nas extremidades protegem essas células da captação pelo fígado. Quando os eritrócitos estão velhos e prontos para a destruição e reposição, ocorre a remoção dos ácidos siálicos terminais pela enzima sialidase expondo resíduos de galactose, que interagem com receptores dos hepatócitos ${ }^{18}$ (Figura 5).

Outro exemplo da importância dos ácidos siálicos refere-se ao processo de inflamação. Neste caso, os leucócitos que circulam na corrente sanguínea devem se ligar à superfície de células endoteliais (células que revestem os vasos sanguíneos) antes de migrarem entre

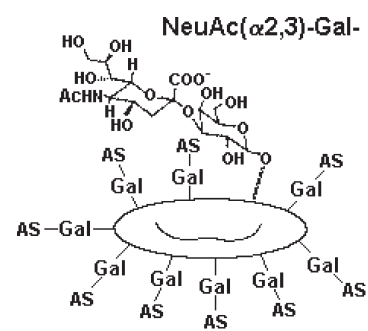

Eritrócitos "novos"

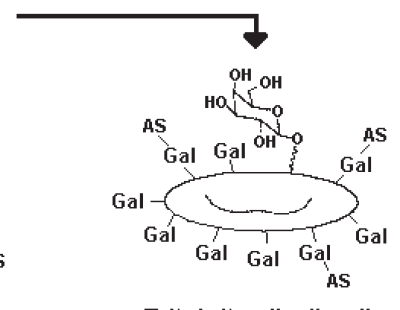

Eritrócitos "velhos"

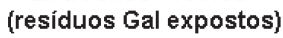

\section{Destruição dos} eritrócitos "velhos"
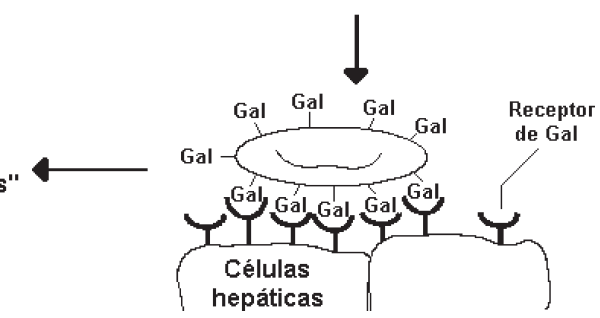

Figura 5. Formação de eritrócitos circulantes não-sililados

as células para chegar ao local atingido ${ }^{1-3,17,19}$ (Figura 6). No local da inflamação, a selectina $\mathrm{P}$ da superfície de células endoteliais interage com um resíduo de ácido siálico específico das glicoproteínas dos leucócitos circulantes. Esta interação diminui a velocidade de difusão dos leucócitos, devido à adesão e à rolagem destes ao longo do revestimento endotelial dos capilares. Uma segunda interação entre as moléculas das integrinas na membrana plasmática dos leucócitos e uma proteína de adesão na superfície das células endoteliais diminui o movimento dos leucócitos, permitindo sua passagem através da parede do capilar para os tecidos danificados, para iniciar uma resposta imune. Fármacos que interferem na ligação selectinacarboidrato auxiliam no tratamento de doenças inflamatórias crônicas causadas por leucócitos hiperativos ${ }^{17,19}$.

De todos os processos biológicos mediados por ácidos siálicos, os que despertaram maior interesse e se tornaram alvo de estudos mais detalhados, a maior parte deles ainda em andamento, são referentes à infecção dos humanos por bactérias e vírus. Por exemplo, a toxina pertussis, produzida por Bordetella pertussis, bactéria que causa a coqueluche, penetra na célula alvo somente depois de interagir com um oligossacarídeo contendo uma unidade de ácido siálico terminal. A compreensão de detalhes dos sítios de ligação das toxinas (lectinas) aos oligossacarídeos, ainda incipiente, pode permitir, por engenharia genética, a produção de toxinas análogas para uso em vacinas. As toxinas podem ser modificadas de forma a perder a sua potencialidade, tornando-se atenuadas, o que permitiria o desencadeamento de uma resposta imune que proteja o organismo quando exposto à toxina natural ${ }^{1-3}$.

Por outro lado, infecções causadas pelo vírus influenza foram e

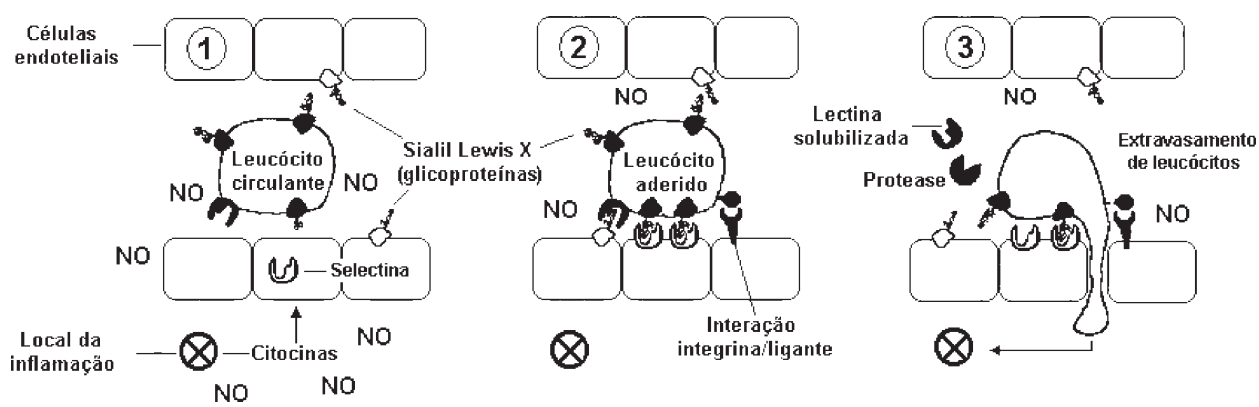

Figura 6. Cascata de reações envolvidas em um processo inflamatório 
estão sendo muito melhor estudadas, e a função dos ácidos siálicos abriu novas possibilidades para o entendimento de algumas doenças.

\section{OS ÁCIDOS SIÁLICOS COMO FONTE DE INSPIRAÇÃO PARA O DESENHO DE FÁRMACOS CONTRA A GRIPE}

\section{A gripe e seu agente etiológico}

A influenza é uma virose respiratória aguda que ocorre durante todo ano, sendo popularmente conhecida como gripe. O termo influenza, do latim del fredo (frio), relaciona a doença ao inverno. Já o termo gripe tem sua origem no russo khripu, que quer dizer rouquidão ${ }^{20}$. É considerada uma doença de alta transmissibilidade, principalmente em ambientes fechados, e manifesta-se sob forma de surtos e epidemias, sendo sua transmissão através do contato com pessoas gripadas, por meio do ar ou da saliva.

A gravidade da doença durante as epidemias e pandemias (epidemias em vários continentes) de influenza é bastante variável, causando desde quadros de rinofaringite leve até pneumonia viral, com complicações fatais. A Figura 7 ilustra algumas doenças que podem surgir como consequiência de um quadro de infecção com o influenza ${ }^{21}$.

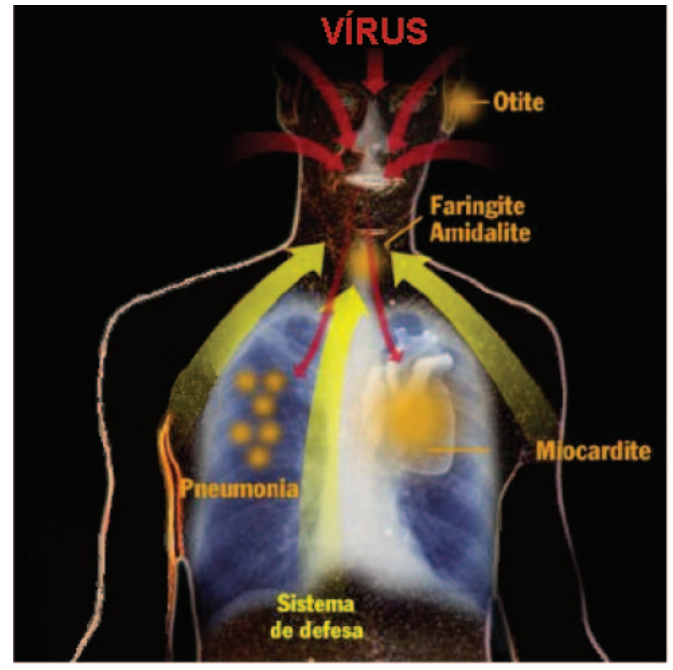

Figura 7. Possíveis conseqüências da infecção pelo vírus influenza. Reproduzido da ref. 21, com permissão do Departamento de Pesquisa, Arquivo Editorial da Revista Isto É

Em 1918, a gripe espanhola matou 30 mil pessoas no Brasil. Foi a mais devastadora pandemia do século XX, totalizando 21 milhões de mortes em todo mundo, ou seja, a doença matou duas vezes mais pessoas que a I Guerra Mundial. Estima-se que, anualmente, cerca de $10 \%$ da população mundial seja acometida pela influenza. Os sintomas mais freqüentes da gripe são caracterizados por febre, calafrios, cefaléia, tosse seca, dor de garganta, congestão nasal ou coriza, mialgias, anorexia e fadiga ${ }^{22}$.

O Myxovirus influenzae, também denominado vírus influenza, é o agente etiológico da gripe. Ele foi isolado pela primeira vez por Hipócrates no ano 412 a.C. Os vírus influenza são partículas envelopadas de RNA de fita simples, subdividindo-se em três tipos: A, B e $\mathrm{C}$, sendo que apenas os tipos A e B têm relevância clínica em humanos. Os vírus influenza A apresentam maior variabilidade e, portanto, são divididos em subtipos de acordo com as diferenças de suas glicoproteínas de superfície, a hemaglutinina e a neuraminidase (Figura 8). Existem quinze tipos de hemaglutinina e nove tipos de neuraminidase identificadas em diferentes espécies animais. Atual- mente são conhecidas três hemaglutininas (H1, H2 e H3) e duas neuraminidases (N1 e N2) presentes nos vírus influenza do tipo A adaptadas para infectar seres humanos ${ }^{22,23}$.

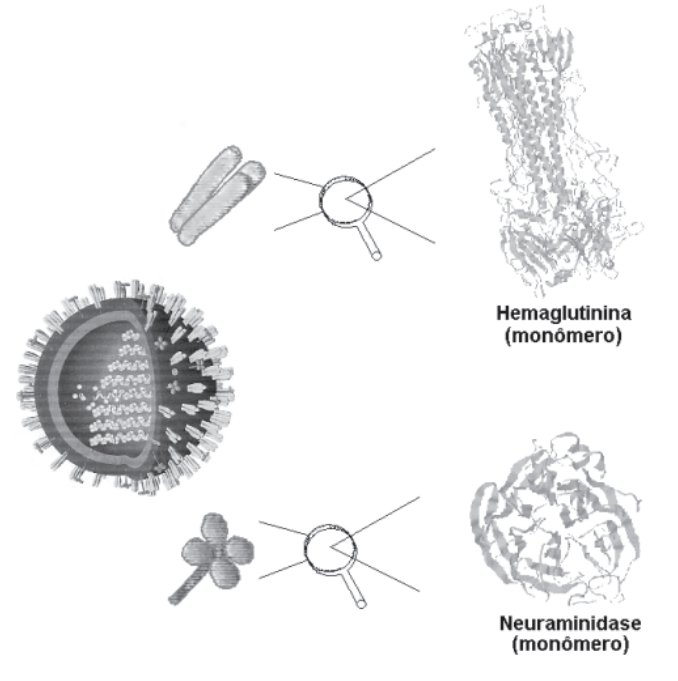

Figura 8. Principais proteínas de superfície presentes no vírus influenza

Que "armas" encontram-se disponíveis contra o vírus da influenza?

Embora a vacinação seja a ferramenta de primeira escolha para a prevenção da influenza, os antivirais específicos são agentes de grande importância no tratamento desta doença. O desenvolvimento de vacinas tem sido apenas parcialmente eficiente no controle da gripe, devido à alta capacidade de mutação que o vírus apresenta ${ }^{24}$. Atualmente estão disponíveis na Europa e Estados Unidos quatro fármacos antivirais específicos para a influenza: os fármacos clássicos, amantadina (4) e rimantadina (5), e os antivirais de segunda geração, zanamivir (6) e oseltamivir (7) (Figura 9). Os antivirais 6 e 7 foram licenciados pelas autoridades sanitárias brasileiras, encontrando-se disponíveis no mercado desde o ano de $2000^{24}$ (Figura 9).

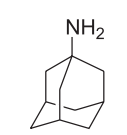

Amantadina (4)

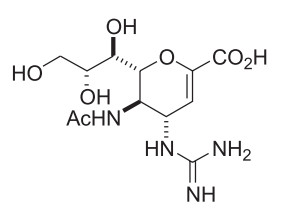

Zanamivir (6)

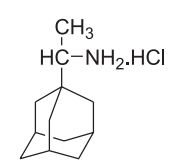

Rimantadina (5)

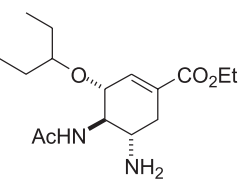

Oseltamivir (7)
Figura 9. Fármacos clássicos amantadina (4) e rimantadina (5), e antivirais de segunda geração zanamivir (6) e oseltamivir (7)

A amantadina (4) e a rimantadina (5) (esta última não registrada na Europa) são recomendadas na profilaxia da infecção por Myxovirus influenzae tipo A, não tendo indicação em infecções por vírus B ou $\mathrm{C}^{25}$. Ambas atuam inibindo a replicação viral através da inativação do canal iônico (proteína $\mathrm{M}_{2}$ ) do vírus ${ }^{26}$. Porém, o vírus é capaz de criar facilmente resistência, in vitro e in vivo, a esses fármacos e as variantes resistentes do vírus são transmissíveis e patogênicas ${ }^{27,28}$. Os eventos adversos associados ao uso de amantadina (4) e rimantadina (5) incluem transtornos do sistema nervoso central (SNC) 
e gastrointestinal (náuseas e vômitos). Assim, o baixo espectro de ação, o rápido desenvolvimento de resistência viral e o fato de provocarem reações adversas têm restringido a utilização destes fármacos na prática clínica ${ }^{29-31}$.

Os antivirais de segunda geração, por sua vez, representam novas opções para o tratamento e/ou profilaxia da gripe. Estes são integrantes de uma nova classe de fármacos específicos contra os vírus influenza A e B, classificados como inibidores de neuraminidase $(\mathbf{N})$, tendo sido aprovados para o tratamento da influenza nos Estados Unidos e no Brasil em 1999 e 2000, respectivamente ${ }^{32}$.

\section{Compreender para combater - o ciclo de vida do vírus influenza e a evolução dos fármacos contra a gripe}

O vírus influenza freqüentemente é transmitido de uma pessoa para outra via gotículas de água contaminadas que são expelidas durante um espirro ${ }^{30}$ (A, Figura 10). O vírus penetra no sistema respiratório ou nos olhos através das mucosas e então atinge a corrente sanguínea, aumentando a produção de secreção e provocando o primeiro sintoma da gripe: a coriza. Na corrente sangüínea, os vírus atacam as células $^{30}$ (B, Figura 10). Duas principais enzimas virais estão envolvidas no processo de infecção: a hemaglutinina ${ }^{33,34}$ e a neuraminidase ${ }^{35-38}$ (Figuras 8 e 10). Ambas as enzimas atuam e reconhecem resíduos de ácidos siálicos presentes nas glicoproteínas das células a serem infectadas e induzem a fusão e incorporação do envelope viral pela célula (C, Figura 10). Dentro da célula o vírus libera o seu material genético, o RNA, que é internalizado juntamente com algumas proteínas virais no núcleo. As proteínas virais promovem a duplicação do RNA viral e produzem RNA viral mensageiro que utiliza a "maquinaria celular" do hospedeiro para sintetizar novas proteínas virais. Estas proteínas, juntamente com as cópias de RNA viral, formam então cópias do vírus que saem da célula infectada e vão infectar outras célu$\operatorname{las}^{30}$ (D-K, Figura 10). O reconhecimento de que as enzimas hemaglutinina e a neuraminidase são de fundamental importância para o sucesso da infecção abre a possibilidade de se interferir na atividade de uma ou ambas enzimas do ciclo de vida do vírus influenza, o que pode tornar lento o processo de invasão celular, permitindo ao sistema imune tempo suficiente para ser efetivo contra o vírus. E foi justamente conhecendo o ciclo de vida do vírus influenza e compreendendo como é possível intervir neste ciclo que, hoje, se tem no mercado farmacêutico dois medicamentos para o tratamento da gripe: o Relenza ${ }^{\circledR}$ [zanamivir (6)] e o Tamiflu ${ }^{\circledR}$ [oseltamivir (7)], da Roche e da

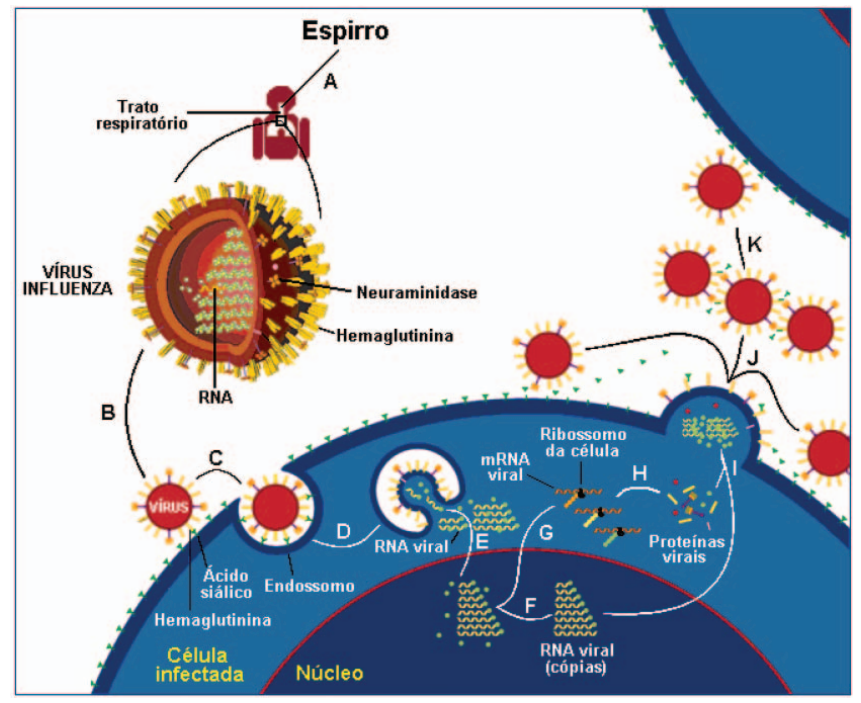

Figura 10. Ciclo de vida do vírus influenza. Adaptado da ref. 30
GlaxoSmithKline, respectivamente. Além desses, outros compostos encontram-se em fase 3 dos testes clínicos ${ }^{14}$.

\section{DESENHANDO FÁRMACOS ANTIINFLUENZA}

A partir da versatilidade de funções dos ácidos siálicos, torna-se de grande interesse o estudo não somente do seu processo de biossíntese, descrito anteriormente, como também a proposta de possíveis intervenções terapêuticas que possam auxiliar no tratamento de doenças associadas ao reconhecimento destas moléculas.

As últimas três décadas revelaram novas funções biológicas para os ácidos siálicos, o que tem motivado o desenvolvimento de metodologias sintéticas para obtenção destes e de derivados, de forma a permitir traçar um esboço de como e quais são os requisitos mínimos para que estes carboidratos interajam com os seus receptores e desencadeiem a mensagem que levará às respostas biológi$\operatorname{cas}^{11,14,15}$. A Figura 11 mostra uma evolução acentuada no número de publicações e requerimentos de patentes associados a processos de síntese e utilização de ácidos siálicos ${ }^{39}$.

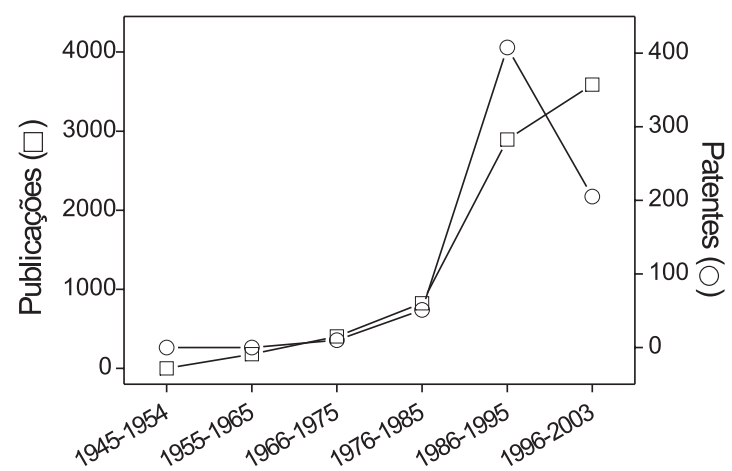

Figura 11. Evolução do número de publicações e de requerimento de pedidos de patente relacionados à síntese e utilização de ácidos siálicos, segundo dados divulgados pela ISI Web of Knowledge . $^{39}$

Como muitos ácidos siálicos naturais são rapidamente degradados por enzimas digestivas, plasmáticas ou glicosidases celulares, um grande avanço se deu com a utilização de glicomiméticos, moléculas que contêm os requisitos estruturais mínimos para interação com uma dada biomolécula. Os glicomiméticos podem apresentar vantagens quando comparados a oligossacarídeos de ocorrência natural no organismo, a saber: maior estabilidade na presença de enzimas degradativas; maior afinidade pela biomolécula em investigação em função de seu desenho; modulação dos parâmetros de biodisponibilidade e farmacocinética por modificações estruturais; maior semelhança a intermediários de reações enzimáticas; etc ${ }^{17}$.

$\mathrm{O}$ entendimento de como os carboidratos interagem com seus receptores protéicos (Figura 12A) fornece informações importantes para o desenho de carboidratomiméticos. Baseado neste conhecimento prévio, duas podem ser as abordagens dadas ao desenho destes miméticos ${ }^{17}$ : uma compreendendo os compostos com um razoável grau de similaridade com o carboidrato (Figura 12B) e outra onde toda a porção do carboidrato é alterada, mantendo-se apenas os grupos funcionais envolvidos nas interações fundamentais entre o carboidrato e seu receptor, em suas formas originais ou na forma de isósteros (Figura 12C).

Na Figura 13 encontram-se apresentadas as interações importantes entre o sítio ativo da hemaglutinina do vírus influenza e o receptor sialosídeo da molécula hospedeira. Porém, o sítio ativo da hemaglutinina apresenta uma afinidade fraca por sialosídeos monoméricos (com apenas um resíduo de ácido siálico), o que difi- 


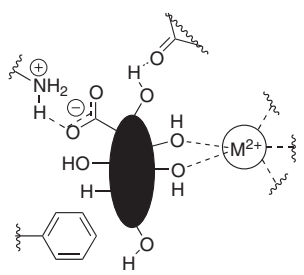

A: Ligante natural

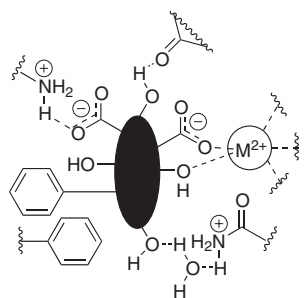

\section{B: Desoxicarboidrato com novos grupos funcionais}

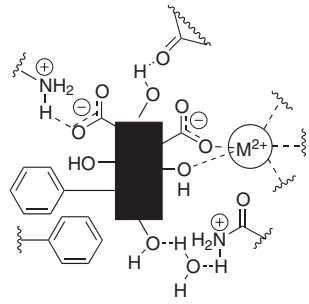

\section{C: Novo núcleo com grupos essenciais e novos grupos funcionais}

Figura 12. Estratégias gerais usadas para o desenho de glicomiméticos

culta o desenvolvimento de sialilmiméticos que atuem de forma eficiente sobre a hemaglutinina ${ }^{40-42}$. Muitos miméticos de ácidos siálicos monoméricos mostraram apenas uma baixa eficácia na prevenção da infecção viral. Por outro lado, uma variedade de estruturas como lipossomos e polímeros (Figura 14), tendo vários resíduos de ácidos siálicos ligados (sialosídeos poliméricos) ${ }^{18}$, que foi sintetizada e avaliada quanto à atividade inibitória da hemaglutinina ${ }^{43-46}$ demonstrou, de forma geral, maior eficiência que os sialilmiméticos monoméricos (Figura 14). No entanto, há necessidade de estratégias sintéticas mais elaboradas para a obtenção de sialilmiméticos poliméricos ${ }^{16}$.

Diferentemente da hemaglutinina, a neuraminidase liga-se fortemente a resíduos monoméricos de ácido siálico terminal das glicoproteínas presentes na célula hospedeira. A estrutura cristalográfica da sialidase do vírus influenza foi reportada pela primeira vez em 1983. Evidenciou-se que cada um dos monômeros do homotetrâmero tem seis grupos de quatro folhas $\beta$ pregueadas antiparalelas, arranjadas numa forma helicoidal ${ }^{47,48}$ (Figura 8). Os aminoácidos do sítio ativo têm-se mostrado invariantes nas sialidases de todas as cepas de ambos os vírus, influenza A e B. Além disso, um razoável número de aminoácidos que fornece suporte à estrutura do sítio ativo é conservado.

A Figura 15 apresenta o estado de transição proposto para o mecanismo enzimático de ação da neuraminidase do vírus influenza ${ }^{14,47-51}$. Em nível molecular, a neuraminidase promove a quebra da ligação glicosídica da glicoproteína ou do glicolipídio. Há perda do resíduo de ácido siálico terminal com formação de um intermediário, o cátion endocíclico sialosil (8), que é subseqüentemente interceptado pela água levando à formação de $\alpha$-Neu5Ac $(\alpha \mathbf{1})$. O $\alpha \mathbf{1}$ converte-se ao anômero $\beta$-Neu5Ac ( $\beta \mathbf{1})$ que é termodinamicamente mais favorável. A proposta da existência do intermediário catiônico 8 (Figura 15) é fundamentada por experimentos de cinética enzimática, experimentos de $\mathrm{RMN}^{49-51}$ e por métodos computacionais ${ }^{52}$. Acredita-se que este intermediário é estabilizado no sítio ativo da neuraminidase através de interações iônicas entre resíduos de aminoácidos carregados negativamente e o cátion intermediário $(\mathbf{8})^{14,15}$.

Um dos primeiros inibidores de sialidase do vírus influenza foi o ácido 2,3-didesidro-2-desoxi-D- $N$-acetilneurâminico (Neu5Ac2en, DANA, 9; Figura 16), que mostrou em testes in vitro uma constante de inibição de ordem micromolar $\left(\mathrm{K}_{\mathrm{i}}=10^{-5}\right.$ a $\left.10^{-6} \mathrm{M}\right)$. É proposto que o Neu5Ac2en (9) seja um análogo do estado de transição (Figura 16), com uma dupla ligação entre C2 e C3 planarizando o anel, o que lembra o cátion sialosil $(\mathbf{8})^{14,15,53}$.

Neu5Ac2en (9), contudo, não mostrou seletividade na inibição da sialidase viral e falhou em modelos animais infectados com o vírus influenza ${ }^{14}$. É importante ressaltar que, assim como o Neu5Ac2en (9), grande parte dos inibidores desenhados que apresentaram alguma atividade inibitória requerem a dupla ligação no anel entre o $\mathrm{C} 2$ e $\mathrm{C} 3$, o grupo carboxilato em $\mathrm{C} 2$, um grupo carrega-

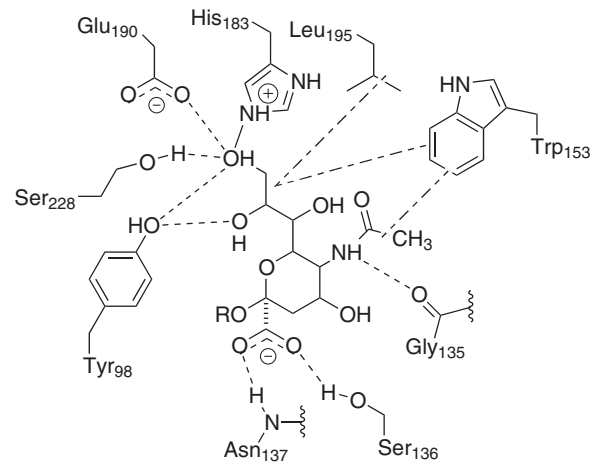

Figura 13. Interações importantes entre a hemaglutinina e o receptor sialosídeo

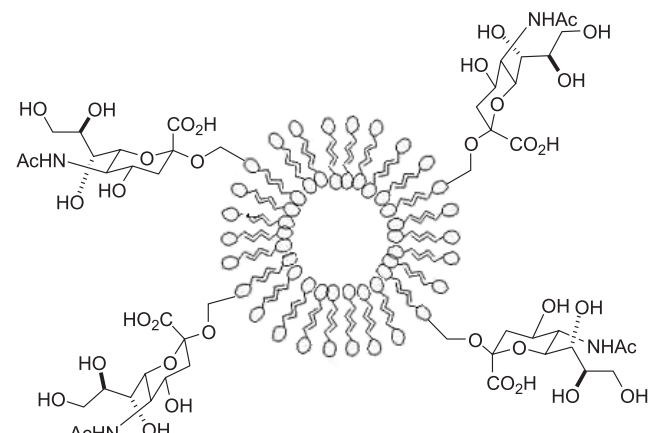

LIPOSSOMO

$\mathrm{IC}_{50}=4,3 \mathrm{mM}$ para hemaglutinina

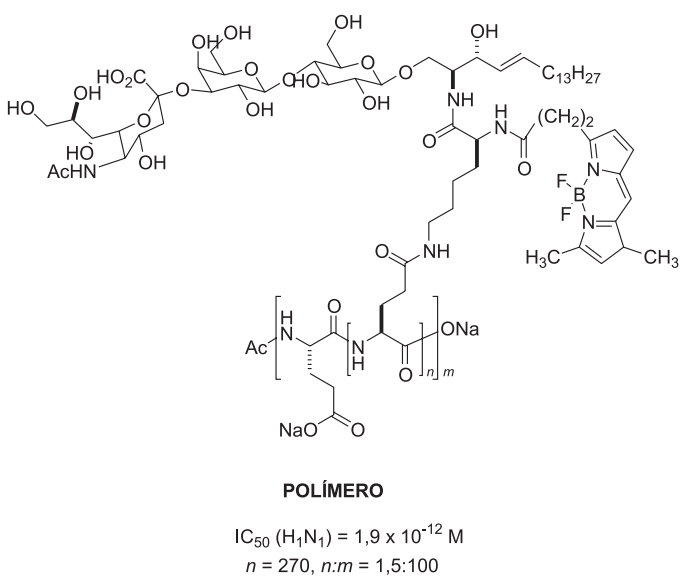

Figura 14. Inibidores da hemaglutinina do vírus influenza: sialosil fosfolipídeo baseado em complexos supramoleculares (lipossomo); sialosil baseado em poliglutamato 


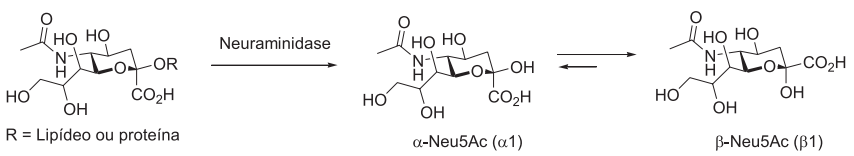
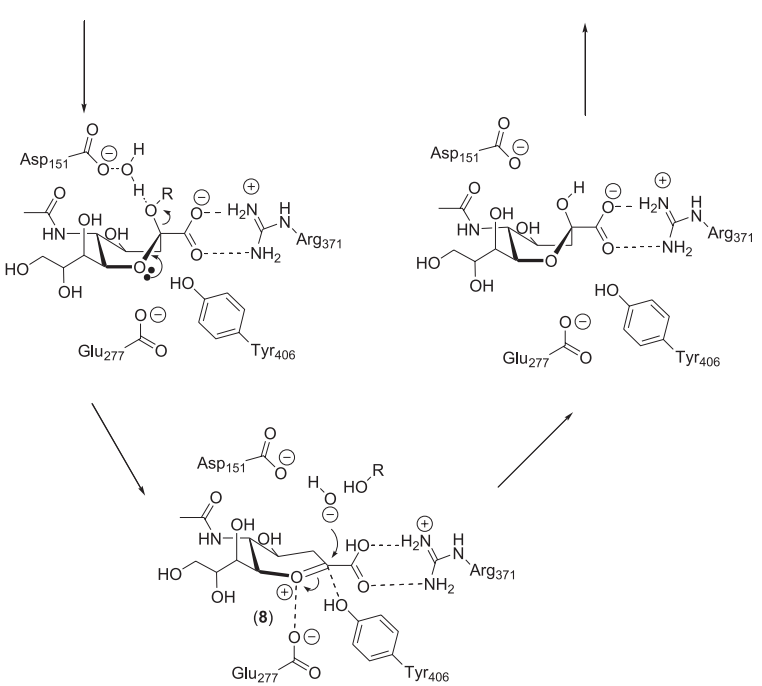

Figura 15. Proposta para o mecanismo enzimático da sialidase do vírus influenza

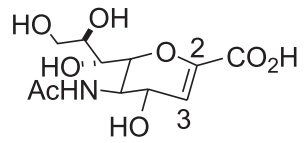

(9)

Figura 16. Estrutura do 2,3-dideidro-2-desoxi-D-N-acetilneurâmico (Neu5Ac2en, DANA, 9)

do positivamente (em condições fisiológicas) em $\mathrm{C} 4$ e o grupo $\mathrm{N}$ acetamido em $\mathrm{C}^{14,15,54}$. A maior exceção é com relação à cadeia trihidroxilada (C7-C9) presente no Neu5Ac2en (9), que pode ser substituída por um grupo ramificado e hidrofóbico ${ }^{54}$.

\section{Inibidores com estruturas derivadas dos ácidos siálicos}

A estrutura cristalina da sialidase do vírus influenza, complexada com os ácidos $N$-acetilneuramínico (Neu5Ac, 1) e Neu5Ac2en (9), provou ser muito útil no desenho racional de fármacos antiinfluenza ${ }^{55}$. Analisando-se a estrutura cristalográfica de sialidases complexadas com os ácidos citados, observou-se que a presença de Neu5Ac (1) ou de Neu5Ac2en (9) não provocou mudanças na geometria do sítio ativo ao qual se ligam os compostos. Foi possível também desenhar um mapa das interações energeticamente mais favoráveis no sítio ativo da enzima, considerando diferentes grupos como o ácido carboxílico, a amina e as hidroxilas.

Comparando este mapa de interações com a estrutura cristalográfica da sialidase do vírus influenza complexada com os compostos Neu5Ac (1) e Neu5Ac2en (9) foi possível prever modificações que, a princípio, pudessem aumentar o efeito inibitório destes compostos sobre a sialidase $^{56}$. Segundo este mapa, existem três áreas principais de interação para o grupo amino, sendo a mais acessível um bolsão situado adjacente ao grupo C4-OH do Neu5Ac (1). Neste sentido, foi desenhado o 4-amino-4-desoxi-Neu5Ac2en (10) (Tabela 1), que mostrou ter uma atividade inibitória para a sialidase do vírus influenza duas vezes maior que a observada para o Neu5Ac2en (9). As interações entre 10 e o sítio ativo da sialidase podem ser observadas na Figura 17. Dado o tamanho do grupo ligado ao $\mathrm{C} 4 \mathrm{e}$, apoiado por estudos de modelagem molecular, foi proposto que este bolsão poderia ser preenchido por um grupo ainda maior e carregado positivamente ${ }^{56}$. von Itzstein e colaboradores $^{56}$, com base nesses estudos, sintetizaram uma série de análogos modificados em C4 (Tabela 1), entre eles o 4-desoxi-4-guanidinoNeu5Ac2en (zanamivir, 6).

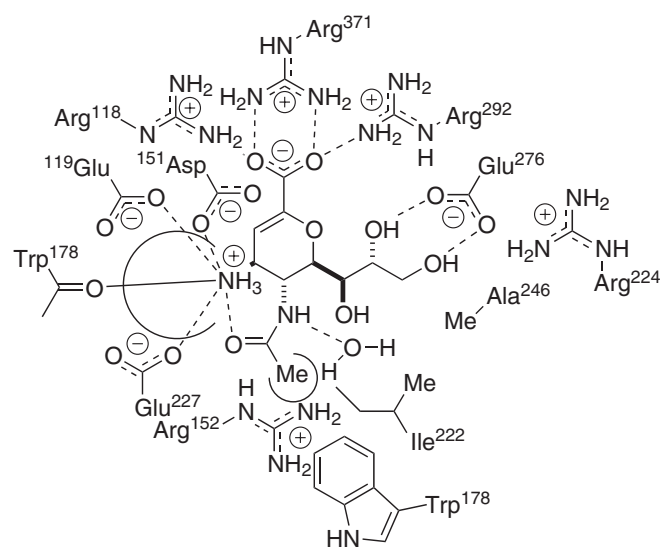

Figura 17. Ligação do composto 10 ao sítio ativo da neuraminidase do vírus influenza

Tabela 1. Análogos de $\mathbf{1 0}$ com diferentes substituintes em C4 e seus respectivos valores de $\mathrm{IC}_{50}$ para a neuraminidase do vírus influenza

\begin{tabular}{cc}
\hline \\
\hline \\
\hline \\
\hline
\end{tabular}

O composto 6 mostrou baixa cinética de ligação e sua constante de inibição experimental foi determinada como sendo aproximadamente $10^{-11} \mathrm{M}$. O zanamivir (6) é administrado por via aérea (inalação de $10 \mathrm{mg}$ ) duas vezes ao dia. É efetivo em curto espaço de tempo ( 0,7 a 1,5 dias) se administrado nas primeiras 30-48 h do ínicio da febre. Os efeitos colaterais estão associados à parte superior do trato respiratório, particularmente no caso de pacientes que apresentam asma, onde há um declínio da força respiratória. O zanamivir (6) não é biodisponibilizado por via oral ${ }^{57}$.

E quanto à seletividade do zanamivir? O organismo humano também possui sialidases e, portanto, os inibidores de sialidases virais devem ser específicos para as sialidases do agente etiológico. $\mathrm{O}$ 
zanamivir (6) mostrou-se altamente seletivo para sialidase viral, apresentando uma constante de inibição de ordem nanomolar $(0,1$ a 1 $\mathrm{nM}$ ), sendo superior aos resultados observados para o protótipo inicial, o composto 9 (Tabela 2$)^{58}$.

Tabela 2. Valores das constantes de inibição $\left(\mathrm{K}_{\mathrm{i}}\right)$ em $\mu \mathrm{M}$ dos compostos 9 e $\mathbf{6}$ para neuraminidases de diferentes fontes

\begin{tabular}{llcc}
\hline Fonte de Neuraminidase & $\begin{array}{c}\text { DANA }(\mathbf{9}) \\
{\left[\mathrm{K}_{\mathrm{i}}(\mu \mathrm{M})\right]}\end{array}$ & $\begin{array}{c}\text { Zanamivir (6) } \\
{\left[\mathrm{K}_{\mathrm{i}}(\mu \mathrm{M})\right]}\end{array}$ \\
\hline Vírus & Influenza A & 4 & $0,001-0,0001$ \\
& Influenza B & 20 & 0,01 \\
\multirow{4}{*}{ Bactéria } & V. cholerae & 3 & 60 \\
& C. perfringens & 8 & $>100$ \\
Mamífero & Fígado de carneiro & 8 & 300 \\
& Placenta humana & 6 & 500 \\
\hline
\end{tabular}

Há um grande número de compostos sintetizados, tendo como protótipo o Neu5Ac2en (9) e que foram testados como inibidores de sialidase do vírus influenza ${ }^{14-16}$. Uma importante modificação realizada nestes inibidores foi com relação à cadeia tri-hidroxilada (C7C9) presente no Neu5Ac2en (9) em C6, que foi substituída por um grupo ramificado e hidrofóbico. Esta substituição foi reportada pela primeira vez por Sollis e colaboradores ${ }^{59}$ para uma série de derivados de 4-desoxi-4-guanidino-Neu5Ac2en carboxiamidas (13) e 4amino-4-desoxi-Neu5Ac2en carboxiamidas (14) (Figura 18).

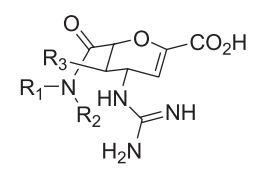

$$
\begin{aligned}
& \mathrm{R}_{3}=\mathrm{NHAc}(14) \\
& \mathrm{R}_{2}
\end{aligned}
$$$$
\mathrm{R}_{3}=\mathrm{NHAc}(13)
$$

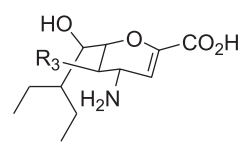

$\mathrm{R}_{3}=\mathrm{NHAC}(\mathbf{1 5})$

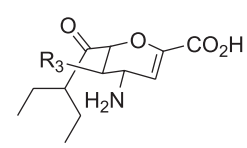

$\mathrm{R}_{3}=\operatorname{NHAc}(16)$
Figura 18. Estruturas dos inibidores 13-16 de neuraminidase do vírus influenza

Esta série de compostos produziu inibidores de sialidases de igual potência ao zanamivir (6) no que se refere ao vírus influenza A, mas foram de duas a três ordens de grandeza menor com relação à cepa viral B. Estudos cristalográficos destes inibidores co-cristalizados com a sialidase do vírus influenza mostraram que o grupo hidrofóbico liga-se no mesmo lugar que se ligava a cadeia tri-hidroxilada (C7C9) do Neu5Ac2en (9), causando uma rotação do resíduo Glu276 [que normalmente forma ligações de hidrogênio com as hidroxilas em C8 e C9 do Neu5Ac2en (9)] e formação de um sal ligado à Arg224 (Figura 19) ${ }^{54,59}$. Isto produz um bolsão hidrofóbico capaz de ajustar um dos braços hidrofóbicos dos substituintes da carboxiamida. Esta reorganização é mais favorável energeticamente, segundo cálculos de dinâmica molecular, para o resíduo de Glu276 da sialidase do vírus influenza $\mathrm{A}$ do que para o da sialidase da cepa $\mathrm{B}^{54}$.

No intuito de potencializar a inibição da sialidase do vírus influenza B, imaginou-se a necessidade da introdução de um grupo mais flexível do que o grupo carboxiamida no lugar da cadeia trihidroxilada ${ }^{60,61}$. Neste sentido, dois compostos, entre outros, derivados do Neu5Ac2en (9) tiveram a cadeia tri-hidroxilada substituída por um grupo alquil ramificado, o álcool 15 e a correspondente for-
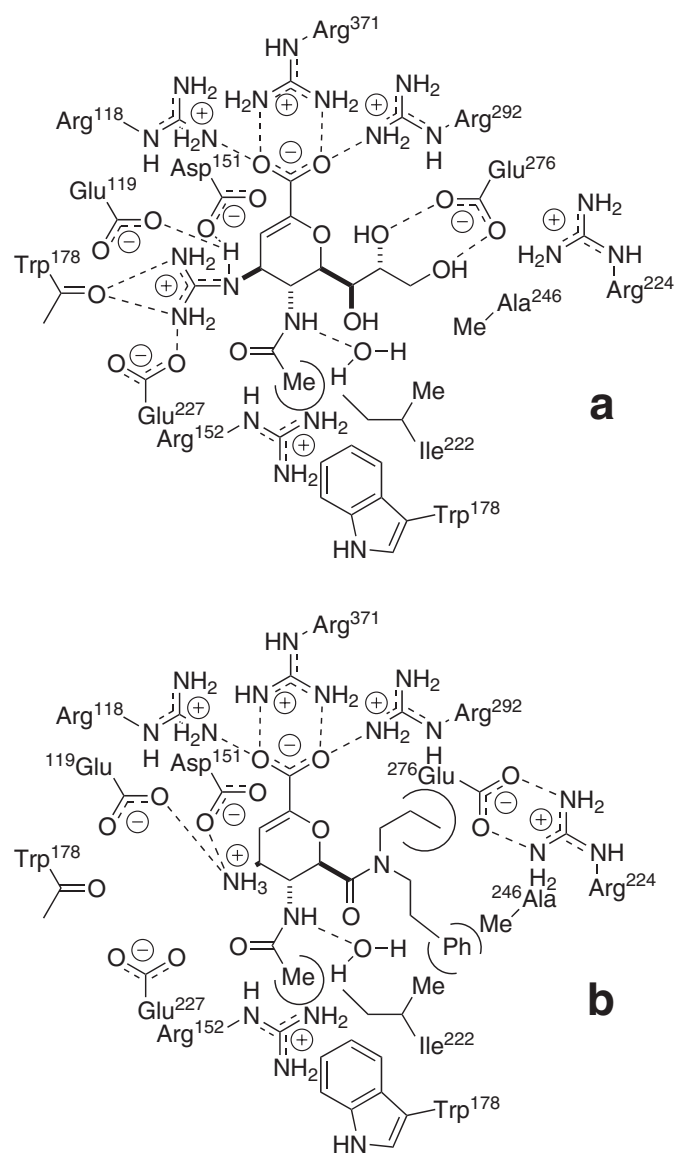

Figura 19. Ligação do zanamivir (a) e um dos derivados de 14, o N-fenil$\mathrm{N}$-propilamida (b) com o sítio ativo da neuraminidase do vírus influenza

ma oxidada, cetona 16. Novamente, ambos os compostos mostraram melhor atividade para a sialidase da cepa A, embora tivesse sido observada considerável atividade contra a cepa $\mathrm{B}^{60}$.

Várias rotas sintéticas já foram descritas para os derivados citados do Neu5Ac (1) e do Neu5Ac2en (9), sendo que os principais materiais de partida utilizados foram o próprio ácido siálico Neu5Ac (1), a glicosamina, o ácido chiquímico e o ácido quínico ${ }^{15}$. Além dos compostos citados (10-16), outros com estruturas similares ao ácido siálico, como por exemplo derivados $S$-glicosídicos ou $N$ glicosídicos ${ }^{15}$ de Neu5Ac (1), também foram preparados. No entanto, não foram alvos de muita atenção por não demonstrarem bons potenciais de inibição do vírus influenza $\mathrm{B}^{14,15}$.

\section{Inibidores com estruturas derivadas do ácido benzóico}

A utilização do ácido benzóico foi uma das primeiras abordagens para a construção de miméticos do anel presente no Neu5Ac2en (9). No Neu5Ac2en (9), a maioria dos substituintes está em posição equatorial e, portanto, mais próxima do plano do anel, o que pode ser mimetizado por substituintes do anel do ácido benzóico. Os estudos cristalográficos dos inibidores baseados na co-cristalização de Neu5Ac2en (9) com as sialidases do vírus influenza mostraram não haver uma forte interação do anel com a proteína. Além disso, o ácido benzóico poderia fornecer um derivado mais hidrofóbico o que o tornaria, a princípio, mais biodisponível ${ }^{14,15}$.

No âmbito desta estratégia, o derivado 17 (Figura 20) foi sintetizado, mas mostrou-se incapaz de inibir a sialidase. Contudo, com a cadeia tri-hidroxilada ausente, como em 18, a inibição observada foi similar àquela descrita para o Neu5Ac2en (9) (Figura 20). Estudos 
de cristalografia do complexo inibidor $\mathbf{1 7}$ e sialidase mostraram que o grupo 3-guanidino [mimetizando o 4-guanidino do zanamivir (6)] realmente liga-se no lugar da cadeia tri-hidroxilada mas, no geral, este composto não se mostrou um bom inibidor. A substituição do grupo tri-hidroxilado por uma cadeia hidrofóbica bifurcada resultou em compostos com razoável atividade inibitória da sialidase do vírus influenza A. Porém, a inibição foi de 3 a 4 vezes menor para a sialidase da cepa $\mathrm{B}^{62,63}$.<smiles>N=C(N)Nc1cc(C(=O)O)cc(C(O)C(O)CO)c1N</smiles><smiles>N=C(N)Nc1ccc(C(=O)O)cc1N</smiles>

Figura 20. Inibidores 17 e 18 de neuraminidase do vírus influenza, com estruturas derivadas do ácido benzóico

\section{Inibidores com estruturas derivadas do cicloexeno}

Os critérios para o desenho dos miméticos derivados do cicloexeno foram, entre outros, a maior biodisponibilidade quando administrados por via oral, o envolvimento de uma química mais simples em sua síntese e a capacidade da dupla ligação no cicloexeno em mimetizar a conformação do ciclo no estado de transição proposto para a interação do Neu5Ac2en (9) com a sialidase do vírus influenza ${ }^{14,15}$

Muitos dos derivados do cicloexeno reportados na literatura tiveram sua atividade inibitória sobre as sialidases do vírus influenza avaliada $^{64-68}$. A partir deste estudo, o antiviral oseltamivir (GS4104, 7) foi desenvolvido e atualmente é comercializado na forma do respectivo sal de fosfato, pela Roche, como Tamiflu ${ }^{\circledR}$. O GS4104 é o éster etílico do componente ativo GS4071 (19), caracterizando-se como um pró-fármaco ${ }^{69}$ (Figura 21).

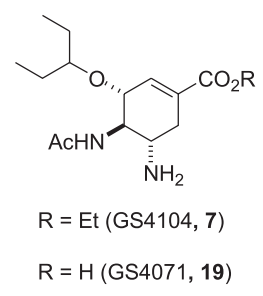

Figura 21. Inibidores GS4104 (7) e GS4071 (19) de neuraminidase do vírus influenza, com estruturas derivadas do cicloexeno

Desconsiderando a estrutura do anel, a maior diferença entre GS4071 (19) e o zanamivir (6) é que o GS4071 (19) tem um grupo hidrofóbico ramificado [o grupo 3-O-(1'-etilpropil)] substituindo a cadeia tri-hidroxilada presente na estrutura do zanamivir. Estudos de raios-X mostraram que o GS4071 (19) liga-se à neuraminidase de maneira análoga ao zanamivir (6) (Figura 19). A cadeia 3-O-(1'etilpropil) [do GS4071 (19)] tem dois importantes sítios de interação com a enzima neuraminidase, devido a sua característica bifurcada: um braço da cadeia 3-O-(1'-etilpropil) está envolvido em interações hidrofóbicas com os grupos Ile222, Arg224 e Ala246, enquanto que o segundo braço provoca um rearranjo do Glu276, produzindo um outro bolsão hidrofóbico com o qual ele interage $\mathrm{e}^{69}$. Este rearranjo envolve a rotação do grupo carboxila do Glu276 para formar um sal entre o grupo guanidino da Arg224 e o Glu276, de modo muito similar ao reportado previamente para os derivados do Neu5Ac2en (9) da série carboxiamida (Figura 19). Naqueles casos, porém, a sialidase do vírus influenza A é inibida aproximadamente duas a três vezes mais do que o observado para a sialidase da cepa $\mathrm{B}$, enquanto que para o GS4071 (19) não há diferença na atividade.

Um dos objetivos do desenho dos compostos derivados do cicloexeno foi o de encontrar um mimético que apresentasse melhor desempenho quanto à biodisponibilidade por via oral. A partir da administração oral em camundongos, o composto GS4071 (19) mostrou biodisponibilidade levemente superior (aproximadamente 5\%) que o zanamivir $(\mathbf{6})^{70,71}$. Já o oseltamivir (GS4104, 7), um prófármaco, é cerca de cinco vezes mais biodisponível por administração oral do que $\mathbf{1 9}^{71,72}$. Por outro lado, a biodisponibilidade do éster do zanamivir (6) não é aumentada ${ }^{71}$.

O Tamiflu ${ }^{\circledR}$ é prescrito como uma cápsula $(75 \mathrm{mg})$, por via oral, duas vezes ao dia num período máximo de cinco dias. Tem a mesma eficácia que o Relenza ${ }^{\circledR}$ e o seu maior efeito colateral consiste em dores de cabeça, náusea e vômito, sendo os dois últimos reduzidos em $10 \%$ se a administração do medicamento for realizada durante as refeições ${ }^{22,73}$.

\section{Inibidores com anéis de 5-membros}

Um dos primeiros relatos de inibidores de sialidases com anéis de 5-membros foi reportado por Yamamoto e colaboradores ${ }^{74}$ (Figura 22), porém, estes compostos mostraram apenas uma leve inibição para as sialidases de ambas as cepas virais, A e B.

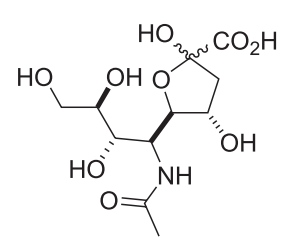

(20)

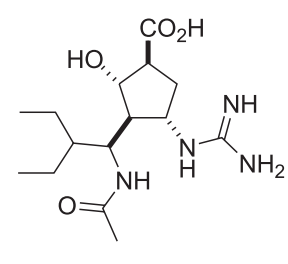

BCX-1812 (21)
Figura 22. Inibidores 20 e 21 de neuraminidase do vírus influenza com anéis de cinco membros

Recentemente o composto BCX-1812 (RWJ270201, 21), que foi desenhado a partir do derivado da furanose (20), mostrou uma excelente atividade inibitória da sialidase do vírus influenza não somente in vitro, mas também in vivo. Este composto encontra-se atualmente em fase 3 na triagem clínica. O desenho do BCX-1812 (21) resultou do estudo e comparação dos complexos derivados da cocristalização da sialidase viral com o composto 20 e com o Neu5Ac2en (9). Babu e colaboradores ${ }^{75}$ realizaram cálculos da conformação destes dois compostos (9 e 20) quando ligados à neuraminidase N9 do vírus influenza A e a sobreposição dos mesmos mostrou que, apesar de serem aparentemente diferentes, apresentam similaridades na organização de seus grupos no espaço (Figura 23).

Após a descoberta do BCX-1812 (21) muitos compostos desta classe foram sintetizados ${ }^{15,74}$. No entanto, análise detalhada da interação de cada um deles com as sialidases mostrou atividade inibitória inferior à descrita para o BCX-1812 (21). A comparação da estrutura do BCX-1812 (21) com o zanamivir (6) e o GS4071 (19) mostra que os grupos importantes para a interação com as sialidases estão presentes: o guanidino (positivo em condições fisiológicas), o carboxilato e o grupo hidrofóbico bifurcado ${ }^{14,15,74}$.

O composto BCX-1812 (21), no modelo de ratos, mostrou potência igual e/ou melhor que a do zanamivir (6) ou oseltamivir (7) apresentando uma boa biodisponibilidade por via oral. Além disso, até o momento, não foram observados efeitos de toxicidade ${ }^{14,76}$.

Outros trabalhos têm mostrado que o anel pirrolidínico pode mimetizar o sistema presente no BCX-1812 2 . O composto 22 (Fi- 


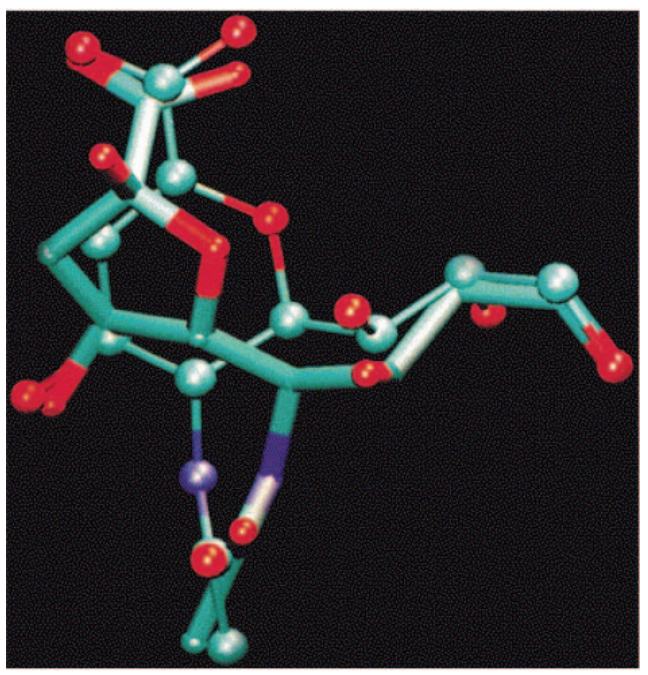

Figura 23. Sobreposição dos compostos Neu5Ac2en (9) (projetado atrás) e 20 (projetado à frente) na conformação das moléculas quando ligadas à neuraminidase $N 9$ do vírus influenza A. Reproduzido da ref. 75, com permissão da American Chemical Society

gura 24), o primeiro deste estudo, mostrou ser ativo inibindo a sialidase do vírus influenza A em concentrações da ordem micromolar. Utilizando-se dados de inibição, estrutura cristalográfica e métodos de modelagem molecular, os pesquisadores definiram um modelo que pôde tanto desenhar novos compostos com núcleo pirrolidínico, quanto predizer suas respectivas atividades. A partir deste modelo foram propostos dois novos compostos representados pelos protótipos 23 e 24 (Figura 24). Aproximadamente 600 derivados foram sintetizados através de uma abordagem de química combinatorial. Estes compostos mostraram uma acentuada tendência em inibir a sialidase do vírus influenza A com maior eficiência ${ }^{77}$.

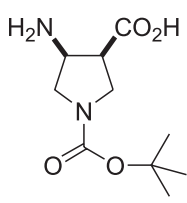

(22)

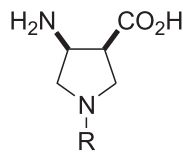

(23)

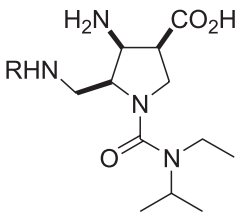

(24)
Figura 24. Inibidores de neuraminidase do vírus influenza, baseados em anéis pirrolidínicos

\section{Outros tipos de inibidores}

Algumas benzoquinonas e hidroquinonas, sendo a mais potente a terc-butilidroquinona, têm mostrado capacidade de inibir, in vitro, determinados subtipos de hemaglutininas, modificando sua conformação. No entanto, falharam nos ensaios in vivo. Outras moléculas, como 25 (Figura 25), também inibiram a replicação do vírus influenza

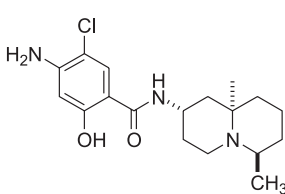

(25)

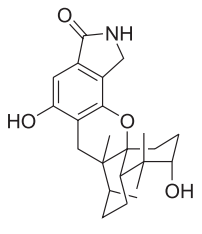

(26)

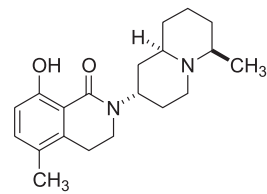

(27)
Figura 25. Produtos naturais que têm apresentado atividade inibitória para hemaglutinina do vírus influenza através deste mecanismo ${ }^{78,79}$. Um exemplo mais recente é a estachiflina (26), um derivado sesquiterpênico isolado de fungos do gênero Stachbotrys e que tem apresentado atividade inibitória da hemaglutinina viral ${ }^{80,81}$. Pesquisas em bibliotecas de compostos químicos levaram à identificação de 27, que inibiu o processo de infecção causado por subtipos da hemaglutinina do vírus influenza.

\section{CONCLUSÕES E PERSPECTIVAS}

Das três maiores classes de biomoléculas, os carboidratos são os menos explorados e, até a década de 60, acreditava-se que eles desempenhavam apenas funções passivas, como fontes de energia e como materiais estruturais. Porém, as últimas duas décadas forneceram informações de que os carboidratos estariam desempenhando papéis fundamentais em um grande número de eventos biológicos como infecção bacteriana ou viral, metástase em câncer e processos inflamatórios, entre outros. A compreensão de como os carboidratos estariam envolvidos nestes processos tem permitido o desenvolvimento de intervenções terapêuticas para o tratamento de muitas doenças, infecções, etc. Dentre os carboidratos, os ácidos siálicos têm sido intimamente correlacionados a muitos destes eventos e um grande avanço tem se impulsionado com a síntese e o desenho racional de miméticos destes ácidos e seus conjugados.

Dentre as mais diversas frentes de pesquisas relacionadas à compreensão de como os ácidos siálicos participam em eventos biológicos e das possíveis intervenções nestes processos, os estudos de como estes ácidos agem no processo infeccioso do vírus influenza resultaram no desenvolvimento dos medicamentos Relenza ${ }^{\circledR}$ [zanamivir (6)] da GlaxoSmithKline e o Tamiflu ${ }^{\circledR}$ [oseltamivir (7)] da Roche, além do composto BCX-1812 (21) que se encontra em teste clínico de fase 3. A história e o sucesso da obtenção destes fármacos se deram, em grande parte, como resultado de estratégias multidisciplinares, em especial, síntese orgânica, estudos cristalográficos, modelagem molecular, química computacional, princípios clássicos de química medicinal e estudos de mecanismos enzimáticos.

Os avanços até então obtidos não dão um ponto final à luta que o homem vem travando contra o vírus influenza, pois recentemente foi descrita a existência de cepas resistentes a alguns dos compostos aqui mencionados ${ }^{82,83}$. Certamente, a continuidade e a ampliação dos estudos permitirão sobrepujar estes problemas, e importantes ferramentas para o desenho de novos agentes terapêuticos poderão ampliar as possibilidades de combate eficaz ao agente etiológico da gripe.

\section{AGRADECIMENTOS}

Os autores gostariam de agradecer ao Prof. F. A. S. Coelho e à Profa. R. M. Braga pelas discussões e sugestões que permitiram a elaboração final deste manuscrito. Agradecemos também a todos os autores, editoras e produtores de "artwork" que autorizaram a reprodução de algumas figuras aqui apresentadas.

\section{REFERÊNCIAS}

1. Nelson, D. L.; Cox, M. M.; Lehninger Principles of Biochemistry, $3^{\text {a }}$ ed., Worth Publisher: New York, 2000, cap. 3.

2. Voet, D.; Voet, J. G.; Biochemistry, $2^{\mathrm{a}}$ ed., John Wiley \& Sons Inc.: New York, 1995, cap. 10 e 11.

3. Berg, J. M.; Tymoczko, J.; Stryer, L.; Biochemistry, 5ª ed., W. H. Freeman and Campany: New York, 2002, cap.11.

4. http://superfund.pharmacy.arizona.edu/toxamb/index.html, acessada em Outubro 2001. Imagem adaptada de Peña, C. E.; Carter, D. E.; Ayala-Fierro, F.

5. Dwek, R. A.; Chem. Rev. 1996, 96, 683.

6. Angata, T.; Varki, A.; Chem. Rev. 2002, 102, 439.

7. Varki, A.; FASEB J. 1991, 5, 226. 
8. Maru, I.; Ohta, Y.; Murata, K.; Tsukada, Y.; J. Biol. Chem. 1996, 271, 16294.

9. Keppler, O. T.; Horstkorte, R.; Pawlita, M.; Schmidt, C.; Reutter, W.; Glycobiology 2001, 11, 11R.

10. Jacobs, C. L.; Goon, S.; Yarema, K. J.; Hinderlich, S.; Hang, H. C.; Chai, D. H.; Bertozzi, C. R.; Biochemistry 2001, 40, 12864.

11. DeNinno, M. P.; Synthesis 1991, 583.

12. Gottschalk, A.; Nature 1951, 167, 845.

13. Koeller, K. M.; Wong, C. H.; Chem. Rev. 2000, 100, 4465.

14. Wilson, J. C.; von Itzstein, M.; Curr. Drugs Targets: Infect. Disord. 2003, 4, 389.

15. Kiefel, M. J.; von Itzstein, M.; Chem. Rev. 2002, 102, 471.

16. Kiefel, M. J.; von Itzstein, M.; Prog. Med. Chem. 1999, 36, 1.

17. Sears, P.; Wong, C. H.; Angew. Chem., Int. Ed. 1999, 38, 2300.

18. Mammen, M.; Choi, S. K.; Whitesides, G. M; Angew. Chem., Int. Ed. 1998, 37, 2754.

19. Slee, D. H.; Romano, S. J.; Yu, J.; Nguyen, T. N.; John, J. K.; Rahya, N. K.; Axe, F. U.; Jones, T. K.; Ripka, W. C.; J. Med. Chem. 2001, 44, 2094.

20. Gomes, L.; J. Pneumol. 2001, 27, 97.

21. Revista ISTOÉ; $O$ caminho do influenza: ameaça antiga. Reportagem de capa, Janeiro, 2000, 1581.

22. Forleo-Neto, E.; Halker, E.; Santos, V. J.; Paiva, T. M.; Toniolo-Neto, J.; Rev. Soc. Bras. Med. Trop. 2003, 36, 267.

23. Cox, N. J.; Subbarao, K.; Infectious Disease Clinics of North America 1999, $354,1277$.

24. Hayden, F. G.; Belshe, R. B.; Clover, R. D.; Hay, A. J.; Oakes, M. G.; Soo, W. N.; Engl. J. Med. 1989, 321, 1696.

25. Keyser, L. A.; Karl, M.; Nafziger, A. N.; Bertino Jr., J. S.; Arch. Intern. Med. 2000, 160, 1485 .

26. Hay, A. J.; Wolstenholme, A. J.; Skehel, J. J.; Smith, M. H.; EMBO J. 1985 , 4, 3021.

27. Saul, H.; New Scientist 1995, 26.

28. Demicheli, V.; Jefferson, T.; Rivetti, D.; Deeks, J.; Vaccine 2000, 18, 957.

29. Calfee, D. P.; Hayden, F. G.; Drugs 1998, 56, 537.

30. Laver, W. G.; Bischofberger, N.; Webster, R. G.; Scientific American 1999, $280,78$.

31. Oxford, J. S.; Lambkin, R.; Drugs Discovery Today 1998, 3, 448

32. Centers for Disease Control; Weekly Report 1999, $48,1$.

33. Wilson, I. A.; Skehel, J. J.; Wiley, D. C.; Nature 1981, 289, 366.

34. Wiley, D. C.; Wilson, J. C.; Skehel, J. J.; Nature 1981, 289, 373.

35. Palese, P.; Schulman, J. L.; Boto, G.; Meindl, P.; Virology 1974, 59, 490.

36. Air, G. M.; Laver, W. G.; Proteins: Struct. Funct. Genet. 1989, 6, 341.

37. Corfield, T.; Glycobiology 1992, 2, 509.

38. Liu, C.; Eichelberger, M. C.; Compans, R. W.; Air, G. M.; J. Virol. 1995, 69, 1099.

39. http://isi3.isiknowledge.com/portal.cgi, acessada em Novembro 2003. O termo pesquisado foi "sialic acid".

40. Prichett, T. J.; Brossmer, R.; Rose, U.; Paulson, J. C.; Virology 1987 , 160 , 502.

41. Toogood, P. L.; Galliker, P. K.; Glick, G. D.; Knowler, J. R.; J. Med. Chem. 1991, 34, 3140.

42. Sauter, N. K.; Bednarski, M. D.; Wurzburg, B. A.; Hanson, J. E.; Whitesides, G. M.; Skehel, J. J.; Wiley, D. C.; Biochemistry 1989, $28,8388$.

43. Weinhold, E. G.; Knowles, J. R.; J. Am. Chem. Soc. 1992, 114, 9270.

44. Spevak, W.; Nagy, J. O.; Charych, D. H.; Schaefer, M. E.; Gilbert, J. H.; Bednarski, M. D.; J. Am. Chem. Soc. 1993, 115, 1146.

45. Koketsu, M.; Nitoda, T.; Sugino, H.; Juneja, L. R.; Kim, M.; Yamamoto, T.; Abe, N.; Kajimoto, T.; Wong, C. H.; J. Med. Chem. 1997, 40, 3332.

46. Kamitakahara, H.; Suzuki, T.; Nishigori, N.; Suzuki, Y.; Kanie, O.; Wong, C. H.; Angew. Chem., Int. Ed. 1998, 37, 1524.

47. Varghese, J. N.; Laver, W. G.; Colman, P. M.; Nature 1983, 303, 35.

48. Colman, P. M.; Varghese, J. N.; Laver, W. G.; Nature 1983, 303, 41.

49. Chong, A. K. J.; Pegg, M. S.; Taylor, N. R.; von Itzstein, M.; Eur. J. Biochem. 1992, 207, 335.

50. Griffin, J. A.; Campans, R. W.; J. Exp. Med. 1979, 150, 379.

51. Miller, C. A.; Wang, P.; Flashner, M.; Biochem. Biophys. Res. Commun. 1978, 83, 1479.

52. Taylor, N. R.; von Itzstein, M.; J. Med. Chem. $1994,37,616$.

53. Dyason, J. C.; von Itzstein, M.; Aust. J. Chem. 2001, 54, 663.
54. Sollis, S. L.; Smith, P. W.; Howes, P. D.; Cherry, P. C.; Bethell, R. C.; Bioorg. Med. Chem. Lett. 1996 , 6, 1805.

55. Bossart-Whitaker, P.; Carson, M.; Babu, Y. S.; Smith, C. D.; Laver, W. G.; Air, G. M.; J. Mol. Biol. 1993, 232, 1069.

56. von Itzstein, M.; Dyason, J. C.; Oliver, S. W.; White, H. F.; Wu, W. Y; Kok, G. B.; Pegg, M. S.; J. Med. Chem. 1996, 39, 388.

57. Masuda, T.; Shibuya, S.; Arai, M.; Yoshida, S.; Tomozawa, T.; Ohno, A.; Yamashita, A.; Honda, T.; Bioorg. Med. Chem. Lett. 2003, 13, 669.

58. http://www.omedon.co.uk/influenza/ e referências citadas, acessada em Outubro 2003

59. Smith, P. W.; Sollis, S. L.; Howes, P. D.; Cherry, P. C.; Bethell, R. C.; Bioorg. Med. Chem. Lett. 1996, 6, 1805.

60. Smith, P. W.; Robison, J. E.; Evans, D. N.; Sollis, S. L.; Howes, P. D.; Trivedi, N.; Bethell, R. C.; Bioorg. Med. Chem. Lett. 1999, 9, 601.

61. Smith, P. W. S. L.; Howes, P. D.; Trivedi, N.; Bioorg. Med. Chem. Lett. 2000, 10, 1257.

62. Williams, M.; Bischofberger, N.; Swaminathan, S.; Kim, C. U.; Bioorg. Med. Chem. Lett. 1995 , 5, 2251.

63. Finley, J. B.; Atigadda, V. R.; Duarte, F.; Zhao, J. J.; Brouillette, W. J.; Air G. M.; Luo, M.; J. Mol. Biol. 1999, 293, 1107.

64. Kim, C. U.; Lew, W.; Willians, M. A.; Wu, H.; Zhang, L.; Chen, X.; Escarpe, P. A.; Mendel, D. B.; Laver, W. G.; Stevens, R. C.; J. Med. Chem. 1998, 41, 2451.

65. Lew, W.; Chen, X.; Kim, C. U.; Curr. Med. Chem. 2000, 7, 663.

66. Lew, W.; Wu, H.; Chen, X.; Graves, B. J.; Escarpe, P. A.; MacArthur, H. L.; Mendel, D. B.; Kim, C. U.; Bioorg. Med. Chem. Lett. 2000, 10, 1257.

67. Karpf, M.; Trussardi, R.; J. Org. Chem. 2001, 66, 2044.

68. Hanessian, S.; Wang, J.; Montgomery, D.; Stoll, V.; Stewart, K. D.; Kati, W.; Maring, C.; Kempf, D.; Hutchins, C.; Laver, W. G.; Bioorg. Med. Chem. Lett. 2002, 12, 3425.

69. Kim, C. U.; Lew, W.; Willians, M. A.; Liu, H.; Zhang, L.; Swaminathan, S.; Bischofberger, N.; Chen, M. S.; Mendel, D. B.; Tai, C. Y.; Laver, G.; Stevens, R. C.; J. Am. Chem. Soc. 1997, 119, 681.

70. Ryan, D. M.; Ticehurst, J.; Dempsey, M. H.; Penn, C. R.; Antimicrob. Agents Chemother. 1994, 38, 2270.

71. Li, W.; Escarpe, P. A.; Eisenberg, E. J.; Cundy, K. C.; Sweet, C.; Jakeman, K. J.; Merson, J.; Lew, W.; Williams, M.; Zhang, L.; Kim, C. U.; Bischofberger, N.; Chen, M. S.; Mendel, D. B.; Antimicrob. Agents Chemother. 1998, 42, 647.

72. Mendel, D. B.; Tai, C. Y.; Escarpe, P. A.; Li, W.; Sidwell, R. W.; Huffman, J. H.; Sweet, C.; Jakeman, K. J.; Merson, J.; Lacy, S. A.; Lew, W.; Willians, M. A.; Zhang, L.; Chen, M. S.; Bischofberger, N.; Kim, C. U.; Antimicrob. Agents Chemother. 1998, 42, 640.

73. http://www.tamiflu.com, acessada em Outubro 2003

74. Yamamoto, T.; Kumazawa, H.; Inami, K.; Teshima, T.; Shiba, T. Tetrahedron Lett. 1992, 33, 5791.

75. Babu, Y. S.; Chand, P.; Bantia, S.; Kotian, P.; Dehghani, A.; El-Kattan, Y.; Lin, T. H.; Hutchison, T. L.; Elliott, A. J.; Parker, C. D.; Ananth, S. L.; Horn, L. L.; Laver, G. W.; Montgomery, J. A.; J. Med. Chem. 2000, 43, 3482.

76. Bantia, S.; Parker, C. D.; Ananth, S. L.; Horn, L. L.; Andries, K.; Chand, P.; Kotian, P. L.; Dehghani, A.; El-Kattan, Y.; Lin, T.; Hutchison, T. L.; Montgomery, J. A.; Kellog, D. L.; Babu, Y. S.; Antimicrob. Agents Chemother. 2001, 45, 1162.

77. Wang, G. T.; Chen, Y.; Wang, S.; Gentles, R.; Sowin, T.; Kati, W.; Muchmore, S.; Giranda, V.; Stewart, K.; Sham, H.; Kempf, D.; Laver, W. G.; J. Chem. Soc. 2001, 44, 1192.

78. Luo, G.; Torri, A.; Harte, W. E.; Danetz, S.; Cianci, C.; Tiley, L.; Day, S.; Mullaney, D.; Yu, K. L.; Ouellet, C.; Dextraze, P.; Meanwell, N.; Colonno, R.; Krystal, M.; J. Virol. 1997, 71, 4062.

79. Luo, G.; Colonno, R.; Krystal, M.; Virology 1996, 226, 66.

80. Yoshimoto, J.; Kakui, M.; Iwasaki, H.; Fujiwara, T.; Sugimoto, H.; Hattori, N.; Arch. Virol. 1999, 144, 865.

81. Yoshimoto, J.; Yagi, S.; Ono, J.; Sugita, K.; Hattori, N.; Fujioka, T.; Fujiwara, T.; Sugimoto, H.; Hashimoto, N.; J. Pharm. Pharmacol. 2000, $52,1247$.

82. McKimm-Breschkin, J. L.; Antiviral Res. 2000 47, 1.

83. Baum, E. Z.; Wagaman, P. C.; Ly, L.; Turchi, I.; Le, J.; Bucher, D.; Bush, K.; Antiviral Res. 2003, 59, 13. 